\title{
Quality of Life and Mental Illness in Home Care Professionals
}

\author{
Pelucio $\mathrm{L}^{1 *}$, Nardi $\mathrm{AE}^{1,2}$, Levitan $\mathbf{M}^{1}$, Barreto $\mathrm{I}^{1}$, Rodrigues $\mathrm{M}^{1}$ and \\ Pereira $\mathbf{R}^{1}$ \\ ${ }^{1}$ Researchers of the Laboratory of Panic and Respiration-Institute of Psychiatry, \\ Resistant Depression Ambulatory, Brazil \\ ${ }^{2}$ Professor of the Resistant Depression Ambulatory-National Institute for Science and \\ Technology, Translational Medicine, Brazil
}

\section{Research Article}

Volume 2 Issue 2

Received Date: June 12, 2018

Published Date: July 18, 2018

DOI: $10.23880 / \mathrm{mhrij}-16000122$

*Corresponding author: Luísa Pelúcio, Institute of Psychiatry, Resistant Depression Ambulatory- INCT Translational Medicine, R Visconde de Pirajá, 407/702 - Rio de Janeiro - RJ - 22410-003, Brazil, Tel: 5521-25216147; Email: luisapelucio@hotmail.com

\section{Abstract}

This study has the objective of assessing quality of life and psychopathology in two populations; nursing technicians in training and nursing technicians engaged in home care with patients. The data shows an increase in this type of care, focused on the relevance of the healthcare professionals involved. A total of twenty-one nursing technicians working in home care and twenty-one nursing technicians in training, intending to work in home care, were submitted to three scales assessing anxiety (BAI), depression (BDI) and quality of life (WHOQOL). The results demonstrate that anxiety is more present in younger caregivers, possibly associated with anticipatory anxiety from uncertainty regarding the future. Furthermore, a correlation between higher anxiety levels and higher levels of depression in the group of nursing technicians in training was also found. Moreover, the relationship between these factors and dissatisfaction regarding quality of life of the caregivers was also perceivable, as demonstrated in some domains in both groups. The data seems to indicate that professionals involved in the practice of home care need personal care, given that their practice involves long-term care of others. It should be emphasized that it is important to recognize what constitutes care for the improvement and better understanding of caring for others, this being relevant as a practice in development and increasing globally, with increasing demand for positions for the evaluated populations.

Keywords: Quality of Life; Nursing Technicians; Nursing Technicians in Training Anxiety; Depression 


\section{Mental Health \& Human Resilience International Journal}

\section{Introduction}

Home care is a model of multi-professional medical care with the objective of bringing the patient a similar care structure and care processes to those offered in hospitals, in their home [1]. The home-care model, which is still being reformulated, is an almost exclusively therapeutic practice, based on assistance, rehabilitation or palliative medicine, in response to a pre-existing health problem. It is also necessary to incorporate promotion of health and preventative medicine into its practices. Home care avoids prolonged stays in hospital, interruptions to patient care and distancing of professionals involved in treatment. Moreover, there is also reduced risk of infection from hospital environments, humanization of assistance in the home environment, reduced clinical complications and unnecessary readmissions and optimization of patient recovery time [2-4].

Home care visits have long been one of the instruments used in the ambit of nursing technician care, placing the family at the center of the care [5-9]. In the beginning, the aim was to minimize pain, but home-care actions were subsequently directed at promotion of health and quality of life [10]. Home visits allow the nurse close access to the daily experiences of the patient and their family, including environmental and physical conditions; socioeconomic, spiritual and cultural factors; available resources, hygiene and safety conditions; besides the family dynamic, making it necessary for the nurse to be flexible, prepared and versatile [10-12]. However, this could generate anxiety and other issues related to the nurse's well-being and emotional preparation.

It can be observed that home care has been growing in many countries, with an average of 1.5 million being attended in Brazil, at a growth rate of $8 \%$ per year across the country. (Nead, 2014) According to a survey carried out by Nead (National Nucleus of Home Care Services Núcleo Nacional das Empresas de Serviços de Atenção Domiciliar), the number of companies and health insurance plans offering this service grew from 108, in 2005 , to 400 , in 2013 . The study also points out that revenues in the sector currently exceed 10 billion BRL.

Care in home nursing covers components such as teaching / education for the health of the patient, like how to care and execute procedures, preventing complications and minimizing the effects of the disease $[10,13]$.
Home care in nursing still seems to lack development in the area of education for health, in order to improve its quality [9]. Studies were also found addressing the lack of attention that has been given to demands on the caregivers and, as a result, the difficulty in identifying factors associated with the emotional suffering of the same [14].

In this study there is a prevalence of female, about $95 \%$, due to the professional choice of gender for this function.

One study indicated that $46 \%$ of the caregivers presented significant psychiatric morbidity, this being correlated with psychological morbidity in both groups of caregivers, the behavior and disturbances in mood of the patient being correlated with psychological burden and morbidity [15].

Based on previous data suggesting a high rate of psychopathology among caregivers, the objective of the present study was to assess mental health and quality of life of caregivers at two levels of formation.

\section{Methods}

\section{Participants and Procedures}

In order to assess the caregivers, an anamnesis with basic questions such as length of time in work, use of medication and number of patients was used, along with the following scales: Beck Depression Inventory (BDI), Beck Anxiety Inventory (BAI) and The World Health Organization Quality of Life (WHOQOL-bref) [16-20]. All the participants signed a form of Informed Consent, and the data was analysed using the software STATA 11.0, that is a tool for statistics analyses.

The participants were employees residing in the interior of the state of Rio de Janeiro, in the South Fluminense region, in the cities of Barra Mansa and Volta Redonda. They were recruited through research of multidiscipline teams and through the network of nursing interns.

A total of 42 individuals were assessed ( 40 women and 2 men), whereby 21 participants were nursing technicians in training, that is, not yet working in home care, and 21 were qualified nursing technicians working in the practice of home care. 


\section{Mental Health \& Human Resilience International Journal}

\section{Results}

\section{Socio-Demographic Data (Table 1)}

\begin{tabular}{|c|c|c|c|c|c|}
\hline \multicolumn{2}{|c|}{ For the hole sample } \\
\hline $\begin{array}{c}\text { Age for the } \\
\text { hole sample: } \\
17-48\end{array}$ & $\begin{array}{c}\text { Mean for the } \\
\text { hole sample: } \\
28,59\end{array}$ & $\begin{array}{c}\text { SD for the } \\
\text { hole Sample: } \\
9,98\end{array}$ & $\begin{array}{c}\text { Mean people with } \\
\text { home care } \\
\text { experience: } 1,29\end{array}$ & $\begin{array}{c}\text { SD for people with } \\
\text { home care } \\
\text { experience: } 3,47\end{array}$ & $\begin{array}{c}\text { Mean of years: } \\
1,29 \text { Mean of } \\
\text { patients: } 1,64\end{array}$ \\
\hline \multicolumn{7}{|c|}{ Separated in groups } \\
\hline $\begin{array}{c}\text { Age for those } \\
\text { in training } 17 \\
-47\end{array}$ & $\begin{array}{c}\text { Mean for those } \\
\text { in training } \\
27,65\end{array}$ & $\begin{array}{c}\text { SD for all the } \\
\text { sample: } 9,24\end{array}$ & $\begin{array}{c}\text { Age for those trained } \\
20-48\end{array}$ & $\begin{array}{c}\text { Mean for those } \\
\text { trained: } 32,22\end{array}$ & $\begin{array}{c}\text { SD for those } \\
\text { trained: } 9,14\end{array}$ \\
\hline \multicolumn{6}{|c|}{ Source: data from the research } \\
\hline
\end{tabular}

Table 1: Data description.

\section{Depression and Anxiety in the Entire Sample}

A total of four participants, that is, $9.52 \%$ of all participants, had no level of symptomatology. Thirty people, that is, $71.43 \%$, had at least one of the disorders and 8 individuals, $19.05 \%$, had both disorders. This data may be seen in the Table 2 .

\begin{tabular}{|c|}
\hline $\begin{array}{c}\text { None № depression \% depression № anxiety \% } \\
\text { anxiety }\end{array}$ \\
\hline Mild - moderate $2764.29 \% 3071.43 \%$ \\
\hline Moderate - severe $1228.57 \% 716.67 \%$ \\
\hline Severe $12.38 \% 37.14 \%$ \\
\hline Severe- Anxiety $24.76 \% 24.76 \%$ \\
\hline Source: reserch data \\
\hline
\end{tabular}

Table 2: Data on depression and anxiety for the entire sample.

\section{Anxiety Vs Quality of Life and Depression Vs Quality life}

The data reported in table 3 shows that, as the level of anxiety increases, well-being decreases, especially for the psychological domain, which possesses the highest absolute value of the index $(-0.47)$.

As we can notice through the data, the quality of life tends to decrease with increasing levels of depression. Once again, the psychological domain is the most affected by this relationship with a correlation coefficient of -0.65 .
For quality of life as a whole, the impact of depression appears to be greater than that of anxiety, there being a greater correlation between depression and quality of life. The higher the value of depression, the lower quality of life will be. These results were obtained using the Pearson correlation method ${ }^{1}$ for correlation calculation, and the significance means how much one domain relates to the other. The results are in Table 3.

\begin{tabular}{|c|c|}
\hline $\begin{array}{c}\text { Domain of SF-36 Correlation Coefficient With } \\
\text { Anxiety Correlation With Depression }\end{array}$ \\
\hline Physical & $-0.2361^{*}-0.4211^{* *}$ \\
\hline Psychological & $-0.4707^{*}-0.6583^{* *}$ \\
\hline Social & $-0.3954^{*}-0.5353^{* *}$ \\
\hline Environmental & $-0.4034^{*}-0.5373^{* *}$ \\
\hline Total QL & $-0.4574^{* *}-0.6414^{* *}$ \\
\hline \multicolumn{2}{|c|}{ Source: data of the research } \\
\hline \multicolumn{2}{|c|}{ Note: * significant at $1 \%{ }^{* *}$ significant at 5\%. } \\
\hline
\end{tabular}

Table 3: Analysis of the correlation between physical, psychological, social and environmental domains and levels of anxiety in the entire sample.

\section{Group Data Analyses}

\section{Qualified Group Vs Depression}

A total of 4 (19.05\%) people had depression; 3 (14.29\%) presented mild depression, and 1 (4.76\%) severe. As can be seen from the data in table 3 for the 


\section{Mental Health \& Human Resilience International Journal}

group of qualified professionals, there is the same correlation effect as for the general population, that is, the higher the level of depression, the lower the quality of life. However, depression does not appear to have such an effect on the physical domain, which, as can be seen, has a much lower value than the other domains.

A total of 11 (52.38\%) people had depression; 9 (42.85\%) presenting mild depression, 1 (4.76\%) moderate and $1(4.76 \%)$ severe.

Differently to the qualified group, the group of professionals in training presents a lower correlation with the social domain $(-0.2461)$. Here, as for the sample as a whole, there is also an inverse relationship between depression and quality of life, where the psychological factor is the most affected.
When verifying the correlation with the general level of quality of life, it can be perceived that depression has a greater influence in reducing quality of life for the group of qualified professionals than for the unqualified.

A total of $4(19.05 \%)$ have anxiety, $2(9.52 \%)$ with mild and $2(9.52 \%)$ with moderate anxiety. The only domain that presented a significant correlation was once again the psychological domain $(-0.31)$.

For the unqualified group an increase in anxiety reduces all the quality of life domains. It can also be noted that anxiety reduces the level of quality of life of the unqualified group much more than that of the qualified group. The table with these comparisons is Table 4 . The following calculated correlations indicate that the existence of depression also increases anxiety, especially in the unqualified group.

\begin{tabular}{|c|c|c|c|c|}
\hline & $\begin{array}{c}\text { Depression for the } \\
\text { qualified }\end{array}$ & $\begin{array}{c}\text { Depression for the not } \\
\text { qualified }\end{array}$ & $\begin{array}{c}\text { Anixiety for the } \\
\text { qualified }\end{array}$ & $\begin{array}{c}\text { Anixiety for the not } \\
\text { qualified }\end{array}$ \\
\hline Physical & -0.1645 & $-0.3685^{* *}$ & 0.0526 & $-0.2957^{*}$ \\
\hline Psychological & $-0.4219^{*}$ & $-0.4440^{* *}$ & $-0.3129^{*}$ & $-0.3260^{*}$ \\
\hline Social & $-0.4864^{*}$ & -0.2461 & -0.2685 & -0.2702 \\
\hline Environmental & $-0.4162^{*}$ & $-0.3048^{*}$ & -0.2305 & $-0.3031^{*}$ \\
\hline Total QL & $-0.4635^{*}$ & $-0.3906^{* *}$ & -0.2447 & $-0.3542^{*}$ \\
\hline & \multicolumn{2}{|c|}{ Source: data from the research. } \\
\hline \multicolumn{4}{|c|}{ Note: ** significant at 1\%; significant at 5\%, } \\
\hline
\end{tabular}

Table 4: Correlation between Depression and QL for the qualified group and for the unqualified group.

Correlation among the qualified caregivers (depression Vs anxiety) $=0.5095$ (significant at $1 \%$ )

Correlation among the unqualified caregivers (depression Vs anxiety) $=0.7349$ (significant at $1 \%$ ).

Analyses performed using STATA software 14.0 in the calculation of correlation coefficients.

\section{Discussion}

The present article identified that anxiety is present in younger caregivers from the group in training. This is possibly associated with an anticipatory anxiety, from uncertainty about the future, from the relationship with still being in search of financial stability and professional practice; as demonstrated in a study showing the relationship in which caregivers in training are more prone to anxiety due to inexperience and a state of experimentation [21].

Regarding quality of life of the qualified nursing technicians, the statistical relevance of the correlation with the environmental domain may indicate that the workplace may not offer basic conditions for this professional, in terms of the possibility of resting time and even time for short breaks or meals, given that the work load is an average of 12 to 24 hours per shift. With this being one of the highest domains, it demonstrates that quality of life in relation to environment, leisure time and even financial security is not satisfactory for this population. Quality of life in the psychological domain is also alarming in this assessment, as it is where the participants demonstrated as having issues with self- 


\section{Mental Health \& Human Resilience International Journal}

esteem, dysfunctional thoughts and even problems with their body image.

Among caregivers in training it can also be perceived that there is an inverse relationship between depression and quality of life, whereby the psychological factor is the most affected. However, when considering the correlation with level of quality of life, it can be observed that depression does not have so much influence on reductions in quality of life for this group as anxiety does, an increase in which reduces all quality of life domains. The calculated correlations indicate that the existence of depression also increases anxiety, especially in the unqualified group, as shown in the tables above.

A significant relationship with the psychological domain for both groups of caregivers was observed in the present study, which indicates the necessity for psychological treatment for this population, providing support to help improve professional conduct and the professional relationship with the patient and family. This finding is an indicator of the possible appearance of mental disorders in the absence of such support or even with the support of a professional team.

The present study has limitations regarding sample size, it being a small sample of professionals, which limits generalization of the results. Data from a systematic review, based on twenty-two studies on home care, reported a predominance of descriptive studies (59.4\%), that is, studies permitting the inference that there are themes still to be explored and that expansion and development of studies such as meta-analyses and experimental research are necessary [22]. Various international studies indicate a global scarcity of formal and informal workers in home care, which has been partially covered, in developed countries, through flexibility in immigration policies for healthcare workers $[23,24]$.

It is indicated that there is a necessity to think of ways to support informal caregivers in their work, in guaranteeing a minimal level of qualification, in assuring forms of compensation for occasional financial losses and in the creation of spaces of listening and support, producing permanent education devices [22]. This would involve a necessity for differentiated formation, with orientation courses, as in the population present in this study, to respond to the growing demand of home-care patients. The difficulty of this population in searching for qualified home care is demonstrated by the fact that in Brazil there remains a large number of informal caregivers without the necessary professional training and education.

Analysis of the abovementioned articles indicates a deficit of nursing technicians in the face of growing demand, demonstrating the necessity for the formation of these professionals to meet the demand for home care and act upon the various issues involved in its practice. It can be inferred that home care remains an underexplored theme in the development of studies such as meta-analyses and experimental research. There is a prevalence of female, about $95 \%$, due to the professional choice of gender for this function.

Nursing is predominantly female. The very conceptualization that the profession has given over the years, together with the role of women in different epochs, has contributed to the feminization of this sector. While this is true, the trend of male participation in the category has recently been recorded [25].

\section{References}

1. Tavolari CEL, Fernandes F, Medina P (2000) The development of 'Home Health Care' in Brazil. Journal of Management in Health 9(3).

2. Barbosa, Elisangela (2017) Profissionais da Saúde e Home Care / 1 ed. - Rio de Janeiro, RJ - Revinter BRASIL. Ministério da Saúde. Diretrizes para a atenção domiciliar no sistema único de saúde. Brasília, DF, 2004

3. Freitas AVS, Bittencourt CMM, Tavares JL (2000) Nursing performance in the home care service: experience report / The nursing role in home care internation service: experience report. Rev Baiana Enferm 13(1,2): 103-107.

4. Lacerda MR (2000) Becoming a professional in the home context: nursing care experiences. Florianópolis. Thesis (Ph.D. in Nursing Philosophy) Federal University of Santa Catarina.

5. Egry EY, Fonseca RM (2000) Family, Home Visiting And Nursing: Reviewing The Collective Health Nursing Labour Process. Rev Esc Enf USP 34(3): 233239.

6. Cunha JA (2001) Manual of the Portuguese version of the Beck Scales. São Paulo: Casa do Psicólogo Livraria e Editora. 


\section{Mental Health \& Human Resilience International Journal}

7. Rehem TCMSB, Trad LAB (2005) Home health care: subsidies for a Brazilian basic care project. Cien Saude Colet 10: 231-242.

8. Andrade AM, Silva KL, Seixas CT, Braga PP (2017) Nursing performance in home care: an integrative review of the literature Rev Bras Enferm 70(1): 210219.

9. Lima AN, Silva L, Bousso R (2010) The home visit performed by the community health agent from the perspective of adults and the elderly. Health and Society 19(4): 889-897.

10. Souza CR, Lopes CF, Barbosa MA (2004) The contribution of the nurse in the context of health promotion through the home visit. Revista do UFG Goiânia 6(4-9).

11. Martins CA (2003) Valuing home visitation. Revista Sinais Vitais 48: 8-16.

12. Rice $R$ (2004) Nursing practice in home care: concepts and applications. Luso-Science.

13. Giacomozzi CM, Lacerda MR (2006) The practice of home care for professionals in the family health strategy. Text \& Context of Nursing Florianópolis 15(4): 645-653.

14. Anderson CS, Linto J, Stewart-Wynne EG (1995) A population-based assessment of the impact and burden of caregiving for long-term stroke survivors. Stroke 26(5): 843-849.

15. Draper BM, Poulos CJ, Cole AMD, Poulos RG, Ehrlich F (1992) A comparison of caregivers for elderly stroke and dementia victims. J Am Geriatr Soc 40(9): 896901.

16. Beck AT, Steer RA (1993) Beck Anxiety Inventory, Psychological Corporation, San Antonio, TX.
17. Beck AT, Ward CH, Mendelson M, Mock J, Erbaugh G (1961) An Inventory for Measuring Depression. Archivesof General Psychiatry 4: 53-63.

18. Fleck MP, Leal OF, Louzada $\mathrm{S}$, Xavier $\mathrm{M}$, Chachamovich E, et al. (1999) Development of the Portuguese version of the OMS evaluation instrument of quality of life. Rev Bras Psiquiatr 21(1): 19-28.

19. Fleck MP, Louzada S, Xavier M, Chachamovich E, Vieira G, et al. (1999) Application of the Portuguese version of the World Health Organization quality of life assessment instrument (WHOQOL-100). Rev Saude Publica 33(2): 198-205.

20. The WHOQOL Group (1998) The World Health Organization quality of life assessment (WHOQOL): development and general psychometric properties. Soc Sci Med 46(12): 1569-1585.

21. Isabel Marla batIsta de araújo (2010) PhD thesis in nursing Sciences Care of the Family with an Older Dependent: Nursing Training - University of Porto.

22. Braga PP, de Sena RR, Seixas CT, de Castro EA, Andrade AM, et al. (2016) Supply and demand in home health care. Ciên Saúde Colet 21(3): 903-912.

23. WHO (2008) The Solid Facts: Home Care in Europe. Milan: WHO Regional Of ce for Europe.

24. Lamura G, Polverini $F$ (2005) East to west: the migration of informal caregivers, AARP International, Washington.

25. Lopes, Marta Júlia Marques, Leal, Sandra Maria Cezar (2005) The persistent feminization in the professional qualification of Brazilian nursing. Notebooks pagu 24(1): 105-125.

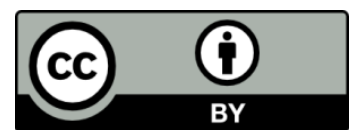

